\title{
Time and chemotherapy treatment trends in the treatment of elderly patients (age $\geqslant 70$ years) with small cell lung cancer
}

\author{
T Yau', S Ashley', S Popat', A Norton', A Matakidou', J Coward' and MER O'Brien*,I \\ 'Lung Unit, Royal Marsden Hospital, Downs Road, Sutton, Surrey SM2 5PT, UK
}

Platinum-based treatment for small cell lung cancer (SCLC) has been established since 1995. This study investigates treatment outcome of elderly patients (age $\geqslant 70$ years) with SCLC over the past 20 years in a large UK cancer centre. Comparison of all-cause survival was assessed in patients presenting between two predefined time periods: 1982-1994 and 1995-2003. All the survival analysis were adjusted for stage and performance status and age if appropriate. Survival between different chemotherapy treatment regimens was compared. A total of 322 elderly patients (31\% of all) registered between 1982-2003 received chemotherapy for SCLC. Patients presenting in 1995-2003 had an overall better median survival (43 vs 25 weeks) and a I-year survival (37 vs 14\%) than patients presenting in $1982-1994(P<0.00 \mathrm{I})$. This applied to patients with both limited and extensive stage disease and all age groups. There was a trend towards the use of more platinum-based treatments in the later cohort but the use of radiotherapy remained constant. Patients who received platinum combinations (Carboplatin or Cisplatin) had significantly improved survival over those who received single agents or other combinations $(P<0.00 \mathrm{I})$ and there was no significant difference between carboplatin and cisplatin $(P=0.7)$. The analysis demonstrates that there has been a significant improvement in survival for elderly patients with lung cancer treated by chemotherapy in the past 20 years despite more very elderly patients being treated with a poorer performance status. This change is probably multifactorial and may be due to the increased use of platinum-based treatment and improved supportive care.

British Journal of Cancer (2006) 94, I8-21. doi: 10.1038/sj.bjc.6602888 www.bjcancer.com

Published online 29 November 2005

(c) 2006 Cancer Research UK

Keywords: age and cancer; chemotherapy; lung cancer

Lung cancer is the main cause of cancer deaths worldwide. The median age at diagnosis in developed countries is approximately 68 years, and as many as $40 \%$ of patients may be older than 70 years (Bunn and Lilenbaum, 2003). In the UK, lung cancer is primarily a disease of the elderly, with a peak incidence between the ages of 70 and 80 years (Cancer Research Campaign, 2001). In the treatment of small cell lung cancer (SCLC), there has been a move to platinum-based treatment (Sundstrom et al, 2002). Local thoracic radiotherapy and prophylactic cranial irradiation now have a place not only in decreasing local recurrence but also in prolonging survival (Pignon et al, 1992; Auperin et al, 1999). Compared to the younger age group, elderly patients have significantly more comorbidity, particularly from pulmonary and cardiovascular disease, and may also demonstrate differences in drug pharmacokinetics. Chemotherapy is often withheld from elderly patients due to the fear of potential toxicities and modest survival advantage (Earle et al, 2000; Bunn, 2002). In addition, there are little published efficacy data for chemotherapy in this patient group, as they have generally been under-represented in clinical trials (Hutchins et al, 1999). This study evaluates the survival time trends and chemotherapy outcomes in elderly patients with SCLC, greater than or equal to 70 years of age, treated at a single institution over a 20 -year period.

* Correspondence: Dr MER O'Brien; E-mail: Mary.O'Brien@rmh.nhs.uk Received 9 September 2005; revised 18 October 2005; accepted 30 October 2005; published online 29 November 2005

\section{PATIENTS AND METHODS}

\section{Patients}

Data on all SCLC patients receiving chemotherapy at the Royal Marsden Hospital (RMH) from 1982 to 2003 were prospectively entered and updated on an electronic database. Recorded data included demographic information, date of presentation to the $\mathrm{RMH}$, stage of disease, performance status (PS), treatment details, and survival status. The diagnosis of SCLC was based on histological or cytological features of the tumour. Tumour tissue was reviewed by a central pathologist until 1998 when central review was discontinued after an internal audit showed no change in diagnosis with review. Thereafter, pathology diagnosis from the original referring hospital was accepted unless clinical picture was inconsistent with referring diagnosis.

Staging was based on both clinical and radiological (CXR and CT scanning) features and was classified according to limited and extensive stage disease defined by the Veterans Administration Lung Study Group (Zelen, 1973). Performance status of patients was graded according to World Health Organization criteria (World Health Organisation, 1979).

Chemotherapy was offered to most patients with SCLC over the 20 -year period. Carboplatin was used instead of cisplatin if patients had poor renal function, deafness, could not tolerate a fluid challenge or could not stay in hospital for the duration of cisplatin pre- and posthydration. Patients were excluded from analysis if they had not had adequate follow-up information or no histological diagnosis. 


\section{Statistical analysis}

Survival was analysed by means of the proportional hazards model (Cox, 1972) and was adjusted for the prognostic factors of stage and PS.

Two predefined time periods, that is patients presenting between 1982-1994 and between 1995-2003 was used for comparison of survival. The year 1995 was chosen as a cutoff point because platinum-based treatment was introduced around this time to treat both limited and extensive stage SCLC patients. Survival by time period, and also by treatment regimen, was adjusted for stage, PS and age. In view of the changes in the local treatment guidelines for elderly patients between the two time periods and the three age groups, imbalances were tested for by means of the Fisher's exact test and the Mann-Whitney (MW) test. Survival was analysed by means of the Cox's proportional hazards model and was adjusted for the prognostic factors of stage and PS.

\section{RESULTS}

\section{Demographics}

Between 1982 and December 2003, 1163 SCLC patients were recorded on the lung unit database. In all, $802(69 \%)$ of these patients were aged $<70$ years and $361(31 \%)$ patients aged 70 years or older. Of the elderly patients, 39 did not receive chemotherapy and they have been excluded from the analysis. This report focuses on the remaining 322 elderly patients (age $\geqslant 70$ years), of which 157 patients presented between 1982 and 1994, and 165 patients between 1995 and 2003.

Table 1 demonstrates patient demographic data stratified by year of presentation. In all, 188 patients $(58 \%)$ were aged $70-74$ years, $108(34 \%)$ were aged $75-79$ years and $26(8 \%)$ were aged $\geqslant 80$ years. The proportion of all patients over the age of 80 years increased from 6 to $10 \%$ between the two time periods. The PS of elderly patients treated in 1995-2003 was overall poorer than those presenting before 1995 .

Table I Demographic data stratified by year of presentation (SCLC treated)

\begin{tabular}{|c|c|c|c|}
\hline & \multicolumn{3}{|c|}{ No. of patients (\%) } \\
\hline & $1982-1994$ & $1995-2003$ & Total \\
\hline Patients & $157(49)$ & $165(5 \mid)$ & 322 \\
\hline \multicolumn{4}{|l|}{ Sex } \\
\hline Male & $95(64)$ & $95(58)$ & $190(59)$ \\
\hline Female & $62(39)$ & $70(42)$ & $132(4 \mid)$ \\
\hline \multicolumn{4}{|l|}{ Age (years) } \\
\hline $70-74$ & $102(65)$ & $86(52)$ & 188 (58) \\
\hline $75-79$ & $45(29)$ & $63(38)$ & $108(34)$ \\
\hline $80+$ & $10(6)$ & $16(10)$ & $26(8)$ \\
\hline \multicolumn{4}{|l|}{ Stage } \\
\hline Limited & $76(48)$ & $88(53)$ & $164(5 \mid)$ \\
\hline Extensive & $81(52)$ & $77(47)$ & $158(49)$ \\
\hline \multicolumn{4}{|c|}{ Performance status } \\
\hline 0 & $10(6)$ & $5(3)$ & $15(5)$ \\
\hline । & $88(56)$ & $52(32)$ & $140(43)$ \\
\hline 2 & $39(25)$ & 77 (47) & $116(36)$ \\
\hline 3 & $15(10)$ & $29(18)$ & $44(14)$ \\
\hline 4 & $4(3)$ & I (I) & $5(5)$ \\
\hline Not known & I (I) & I (I) & $2(1)$ \\
\hline
\end{tabular}

Demographic and treatment data for patients with SCLC is shown for the three age groups in Table 2. The proportion of extensive disease patients treated with chemotherapy decreased with the age group ( $P=0.007$; MW test). Patients in the 70 - to 74-year-age group had a better PS than older patients $(P=0.005$; MW test). Table 3 shows the treatment modalities stratified by time period. There was increased use of platinum compounds over time (1982-94: 48\%, 1995-2003: 75\%). Similar numbers of patients received thoracic and/or prophylactic cranial irradiation.

\section{Survival}

Overall, there has been an improvement in survival after adjusting for stage, PS and age. Patients presenting in 1995-2003 had an overall better median survival (43 vs 25 weeks) and a 1-year

Table 2 Demographic data and treatment modalities in patients with SCLC

\begin{tabular}{|c|c|c|c|c|}
\hline & \multicolumn{4}{|c|}{ No. of patients (\%) } \\
\hline & $\begin{array}{l}\text { Age } 70- \\
74 \text { years }\end{array}$ & $\begin{array}{l}\text { Age } 75- \\
79 \text { years }\end{array}$ & $\begin{array}{l}\text { Age } 80+ \\
\text { years }\end{array}$ & Total \\
\hline Patients & $188(58)$ & $108(34)$ & $26(8)$ & 322 \\
\hline \multicolumn{5}{|l|}{ Stage } \\
\hline Limited & $85(45)$ & $60(56)$ & $19(73)$ & $164(51)$ \\
\hline Extensive & $103(55)$ & $48(44)$ & $7(27)$ & $158(49)$ \\
\hline \multicolumn{5}{|l|}{ PS } \\
\hline 0 & $9(5)$ & $4(4)$ & $2(8)$ & $15(5)$ \\
\hline I & $92(49)$ & 37 (34) & $11(42)$ & $140(43)$ \\
\hline 2 & $67(36)$ & $44(4 I)$ & $5(19)$ & $116(36)$ \\
\hline 3 & $16(9)$ & $20(19)$ & $8(3 \mid)$ & $44(14)$ \\
\hline 4 & $3(3)$ & $2(2)$ & 0 & $5(2)$ \\
\hline Not known & $1(1)$ & I ( $(1)$ & 0 & $2(1)$ \\
\hline \multicolumn{5}{|l|}{ Treatment } \\
\hline Cisplatin-containing regimes & $32(17)$ & $13(12)$ & $3(12)$ & $48(15)$ \\
\hline Carboplatin combinations & $92(49)$ & $49(45)$ & II (42) & $152(47)$ \\
\hline Nonplatinum single agents & $31(17)$ & $40(40)$ & $12(46)$ & $83(26)$ \\
\hline Other nonplatinum combinations & $33(6)$ & $6(6)$ & 0 & $39(12)$ \\
\hline \multicolumn{5}{|l|}{ Radiotherapy } \\
\hline $\begin{array}{l}\text { Thoracic } \\
\text { (within } 3 \text { months of chemo) }\end{array}$ & $17(9)$ & $7(6)$ & $4(15)$ & $28(8)$ \\
\hline $\mathrm{PCl}$ & $13(7)$ & $2(2)$ & 0 & $15(5)$ \\
\hline
\end{tabular}

Table 3 Treatment modalities stratified by year of presentation in SCLC

\begin{tabular}{lccc}
\hline & \multicolumn{3}{c}{ No. of patient (\%) } \\
\cline { 2 - 4 } Treatment & $\mathbf{1 9 8 2 - 1 9 9 4}$ & $\mathbf{1 9 9 5 - 2 0 0 3}$ & Total \\
\hline Cisplatin-containing regimes & $16(10)$ & $32(19)$ & $48(15)$ \\
Carboplatin combinations & $59(38)$ & $93(56)$ & $152(47)$ \\
Nonplatinum single agents & $60(38)$ & $23(14)$ & $83(26)$ \\
Other non-platinum combinations & $22(14)$ & $17(10)$ & $39(12)$ \\
& & & \\
No. of cycles of chemotherapy & $52(33)$ & $36(22)$ & $88(27)$ \\
1 & $22(14)$ & $18(11)$ & $40(12)$ \\
2 & $16(10)$ & $16(10)$ & $32(10)$ \\
3 & $18(11)$ & $41(25)$ & $60(19)$ \\
4 & $18(11)$ & $18(11)$ & $36(11)$ \\
5 & $31(20)$ & $36(22)$ & $67(21)$ \\
$6+$ & $18(11)$ & $10(6)$ & $28(9)$ \\
Local radiotherapy & $3(2)$ & $12(7)$ & $15(5)$ \\
prophylactic cranial irradiation & & & \\
\hline
\end{tabular}




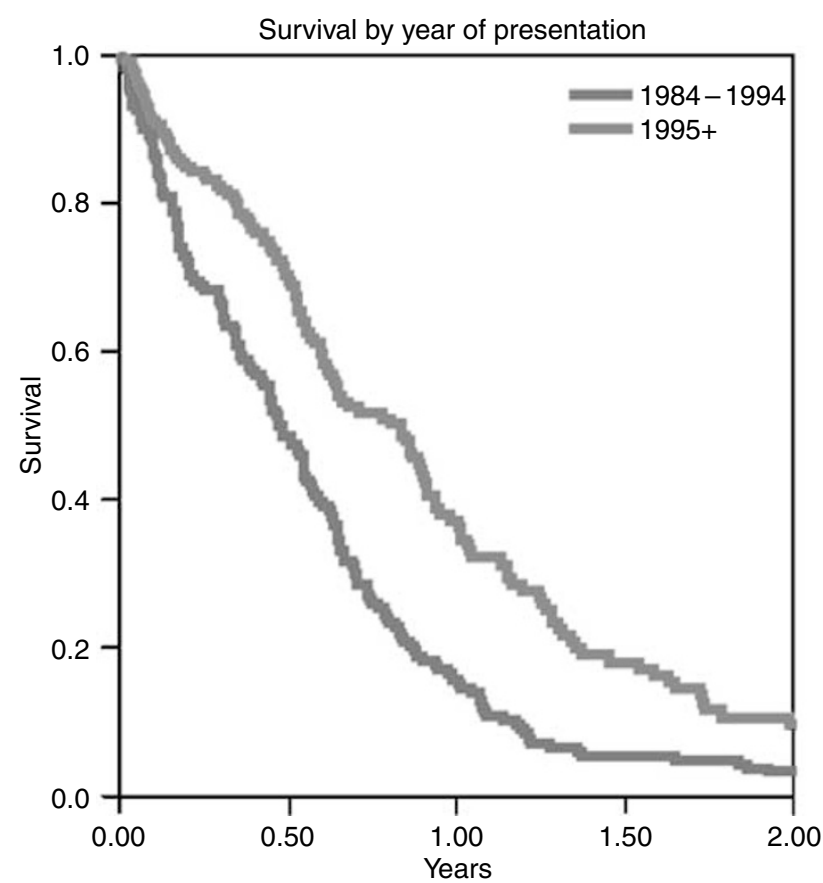

Figure I Survival by year of presentation graph.

Table 4 Survival differences among elderly SCLC patients between 1982-1994 and 1995-2003

\begin{tabular}{|c|c|c|c|}
\hline Year & $1982-1994$ & $1995-2003$ & $P$ values \\
\hline Age $70-74$ years & Weeks & Weeks & \\
\hline MS overall ${ }^{\mathrm{a}}$ & 31 & 47 & 0.001 \\
\hline LD & 33 & 60 & 0.03 \\
\hline ED & 24 & 36 & 0.004 \\
\hline I-year survival & $21 \%$ & $44 \%$ & \\
\hline \multicolumn{4}{|l|}{ Age $75-80$ years } \\
\hline MS overall ${ }^{\mathrm{a}}$ & 25 weeks & 28 weeks & 0.06 \\
\hline LD & 28 & 49 & 0.001 \\
\hline ED & 27 & 27 & 0.7 \\
\hline I year survival & $6 \%$ & $25 \%$ & \\
\hline \multicolumn{4}{|l|}{ Age $>80$ years } \\
\hline MS overall & 9 weeks & 34 weeks & 0.2 \\
\hline $\operatorname{LD} n=19$ & 5 & 62 & 0.02 \\
\hline $\mathrm{ED} n=7$ & 4 & 34 & 1.0 \\
\hline I-year survival & $0 \%$ & $30 \%$ & \\
\hline
\end{tabular}

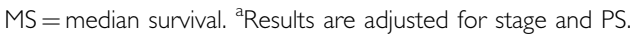

survival (37 vs 14\%) than patients presenting in 1982-1994 $(P<0.001$, Figure 1$)$. This applied to patients with both limited and extensive stage disease. For limited stage 1995-2003 the median survival was 59 weeks compared to 27 in $1982-1994(P<0.001)$ and for extensive disease the same trend was seen with median survivals of 39 vs 23 weeks $(P=0.02)$. Table 4 demonstrates the improvement in survival in different elderly age groups. This survival difference was significant in the 70- to 74-year-age group $(P=0.001)$ but, possibly due to small numbers, the difference did not reach significance in the older age groups.

\section{Survival according to chemotherapy treatment}

Patients who received platinum combinations (carboplatin or cisplatin) had significantly improved survival over those who

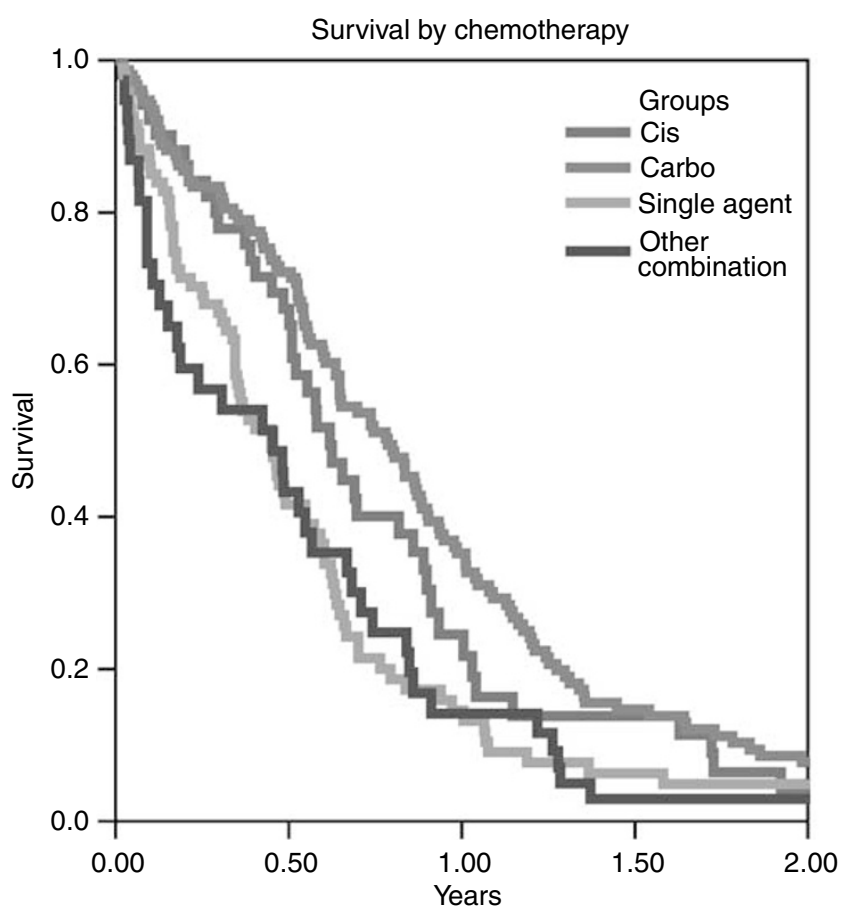

Figure 2 Survival by treatment.

received single agents or other combinations $(P<0.001)$ (Figure 2$)$. There was no significant difference between carboplatin and cisplatin $(P=0.7)$

\section{DISCUSSION}

This study suggests that there has been a significant improvement in survival for SCLC elderly patients (age $\geqslant 70$ years) receiving treatment over the past 20 years despite the trend to treat more of the very elderly and patients with a worse PS. This improvement is still present when patients are controlled for sex, stage and PS, suggesting that this is due to advances in patient management adjunctive therapies and in particular the use of platinum (and carboplatin)-based therapy rather than earlier presentation of the disease.

In SCLC, combination chemotherapy has been an established treatment for decades. In contrast to elderly patients with NSCLC, the majority of elderly patients with SCLC will receive active treatment (chemotherapy and radiotherapy) - only 39/361 of our patients did not receive treatment (Brown et al, 1996). Pooled data of the Southwest Oncology Group (Albain et al, 1990) and CALGB (Spiegelman et al, 1989) showed that age was a significant predictor favouring the younger patient for both limited and extensive disease SCLC although a large French retrospective review of SCLC patients using numerous regimens found no such correlation (Lebitasy et al, 2001). Our median survivals for all these elderly patients are still in the range of reported studies. Single-agent chemotherapy, namely oral etoposide, was initially thought to be a reasonable treatment for elderly patients with SCLC (Smit et al, 1989). However, two large randomised trials demonstrated inferior survival when this regime was compared to combination chemotherapy (Girling, 1996; Souhami et al, 1997) and our data would support this in an nontrial setting. In limited stage SCLC, Siu et al (1996) demonstrated that combination chemotherapy has similar efficacy in both young and elderly patients and Murray et al (1998) showed that treatment toxicities may be minimised while maintaining similar outcomes by giving 
two cycles of chemotherapy followed by radiotherapy, rather than a longer course of chemotherapy. However, subset analysis of an Intergroup trial found that elderly patients (age $>70$ years) obtained similar responses and survival figures to younger patients and that the elderly subgroup did significantly worse when treated by only two cycles of chemotherapy (Yuen et al, 2000). There was no major change in the number of cycles given in our populations over time. In extensive stage SCLC, Pujol et al (2001) found that elderly patients (age $>70$ years) had similar response rates and survival to young patients when they were treated by cisplatin combinations and there was no statistically significant impact of age on these outcomes.

Platinum-based treatment with etoposide has been our treatment of choice for all SCLC patients since around 1995. Outcome improvements in SCLC patients are not restricted to any particular stage or age group. Given that carboplatin was generally used when patients were not considered fit enough for cisplatin the results with carboplatin are very reassuring and the carboplatin etoposide is now the standard in the elderly in our unit. While the benefits of radiotherapy on local disease control have been known for 20 years, the survival benefits of radiotherapy are a more recent addition to the general consensus. (Auperin et al, 1999). In our study, the impact of radiotherapy on the differences in survival between the two cohorts in SCLC patients is negligible as there were a similar proportion of patients who received thoracic and/or prophylactic cranial irradiation between the two cohorts. There are few data in the literature reporting the outcomes of chemotherapy treatment in elderly patients with SCLC. Most studies available include elderly patients with SCLC up to 75 years old. In our study, we have analysed the outcome of 322 elderly patients older than 70 years, and 134 patients older than 75 years with SCLC. This is the largest series in the literature so far.

This improvement in treatment outcomes overall might also be attributed to other factors. Changes in guidelines and different working procedures have resulted in a very large percentage of patients with lung cancer being referred for oncological assessment. Better assessment of comorbidity and PS of patients has resulted in better selection of patients for chemotherapy. There is now better supportive care, such as antiemetics, laxatives, antibiotics, etc. available for these patients, so that courses of treatment of appropriate intensity and duration can be safely administered. The contribution of nutritional status, social and family support are of course not easily quantifiable and difficult to evaluate over a long time period but may also be relevant. Last but not least, advances in the medical oncology treatment of lung cancer, including the use of second-line therapies may also have played a role in the improvement in survival over the recent years in this elderly population (age $\geqslant 70$ years).

In conclusion, the outcome for elderly patients with SCLC in our sector has globally improved. In our experience, carboplatin combinations have as good an outcome and better toxicity profile than other combinations or nonplatinum single agents chemotherapy in the elderly with SCLC.

\section{REFERENCES}

Albain KS, Crowley JJ, LeBlanc M, Livingston RB (1990) Determinants of improved outcome in small-cell lung cancer: an analysis of the 2,580patient Southwest Oncology Group data base. J Clin Oncol 8: 1563-1574

Auperin A, Arriagada R, Pignon JP, Le Pechoux C, Gregor A, Stephens RJ, Kristjansen PE, Johnson BE, Ueoka H, Wagner H, Aisner J (1999) Prophylactic cranial irradiation for patients with small-cell lung cancer in complete remission. Prophylactic Cranial Irradiation Overview Collaborative Group. N Engl J Med 341: 476-484

Brown JS, Eraut D, Trask C, Davison AG (1996) Age and the treatment of lung cancer. Thorax 51: $564-568$

Bunn Jr PA (2002) Chemotherapy for advanced non-small-cell lung cancer: who, what, when, why? J Clin Oncol 20: 23S-33S

Bunn Jr PA, Lilenbaum R (2003) Chemotherapy for elderly patients with advanced non-small-cell lung cancer. J Natl Cancer Inst 95: $341-343$

Cancer Research Campaign (2001) CRC Cancerstats: Lung Cancer and Smoking - UK

Cox D (1972) Regression models and lifetables. J R Stat Soc 34: 187-220

Earle CC, Venditti LN, Neumann PJ, Gelber RD, Weinstein MC, Potosky AL, Weeks JC (2000) Who gets chemotherapy for metastatic lung cancer? Chest 117: $1239-1246$

Girling DJ (1996) Comparison of oral etoposide and standard intravenous multidrug chemotherapy for small-cell lung cancer: a stopped multicentre randomised trial. Medical Research Council Lung Cancer Working Party. Lancet 348: 563-566

Hutchins LF, Unger JM, Crowley JJ, Coltman Jr CA, Albain KS (1999) Underrepresentation of patients 65 years of age or older in cancertreatment trials. N Engl J Med 341: $2061-2067$

Lebitasy MP, Hedelin G, Purohit A, Moreau L, Klinzig F, Quoix E (2001) Progress in the management and outcome of small-cell lung cancer in a French region from 1981 to 1994. Br J Cancer 85: 808-815

Murray N, Grafton C, Shah A, Gelmon K, Kostashuk E, Brown E, Coppin C, Coldman A, Page R (1998) Abbreviated treatment for elderly, infirm, or noncompliant patients with limited-stage small-cell lung cancer. J Clin Oncol 16: 3323-3328

Pignon JP, Arriagada R, Ihde DC, Johnson DH, Perry MC, Souhami RL, Brodin O, Joss RA, Kies MS, Lebeau B, Onoshi T, Osterlind K, Tattersall
MHN, Wagner H (1992) A meta-analysis of thoracic radiotherapy for small-cell lung cancer. $N$ Engl J Med 327: $1618-1624$

Pujol JL, Daures JP, Riviere A, Quoix E, Westeel V, Quantin X, Breton JL, Lemarie E, Poudenx M, Milleron B, Moro D, Debieuvre D, Le Chevalier T (2001) Etoposide plus cisplatin with or without the combination of 4'epidoxorubicin plus cyclophosphamide in treatment of extensive smallcell lung cancer: a French Federation of Cancer Institutes multicenter phase III randomized study. J Natl Cancer Inst 93: 300-308

Siu LL, Shepherd FA, Murray N, Feld R, Pater J, Zee B (1996) Influence of age on the treatment of limited-stage small-cell lung cancer. J Clin Oncol 14: $821-828$

Smit EF, Carney DN, Harford P, Sleijfer DT, Postmus PE (1989) A phase II study of oral etoposide in elderly patients with small cell lung cancer. Thorax 44: 631-633

Souhami RL, Spiro SG, Rudd RM, Ruiz de Elvira MC, James LE, Gower NH, Lamont A, Harper PG (1997) Five-day oral etoposide treatment for advanced small-cell lung cancer: randomized comparison with intravenous chemotherapy. J Natl Cancer Inst 89: 577-580

Spiegelman D, Maurer LH, Ware JH, Perry MC, Chahinian AP, Comis R, Eaton W, Zimmer B, Green M (1989) Prognostic factors in small-cell carcinoma of the lung: an analysis of 1,521 patients. J Clin Oncol 7: 344354

Sundstrom S, Bremnes RM, Kaasa S, Aasebo U, Hatlevoll R, Dahle R, Boye N, Wang M, Vigander T, Vilsvik J, Skovlund E, Hannisdal E, Aamdal S (2002) Cisplatin and etoposide regimen is superior to cyclophosphamide, epirubicin, and vincristine regimen in small-cell lung cancer: results from a randomized phase iii trial with 5 years' follow-up. J Clin Oncol 20: $4665-4672$

World Health Organisation (1979) WHO handbook for reporting results of cancer treatment. Geneva: World Health Organisation

Yuen AR, Zou G, Turrisi AT, Sause W, Komaki R, Wagner H, Aisner SC, Livingston RB, Blum R, Johnson DH (2000) Similar outcome of elderly patients in intergroup trial 0096: cisplatin, etoposide, and thoracic radiotherapy administered once or twice daily in limited stage small cell lung carcinoma. Cancer 89: 1953 - 1960

Zelen M (1973) Keynote address on biostatistics and data retrieval. Cancer Chemother Rep 3 4: $31-42$ 